\title{
The Accessory Optic System Contributes to the Spatio-Temporal Tuning of Motion-Sensitive Pretectal Neurons
}

\author{
Nathan A. Crowder, ${ }^{2}$ Hugo Lehmann, ${ }^{1}$ Marise B. Parent, ${ }^{1,2}$ and Douglas R.W. Wylie ${ }^{1,2}$ \\ ${ }^{1}$ Department of Psychology and ${ }^{2}$ Division of Neuroscience, University of Alberta, Edmonton, T6G 2E9 Alberta, Canada
}

Submitted 10 August 2002; accepted in final form 9 December 2002

Crowder, Nathan A., Hugo Lehmann, Marise B. Parent, and

Douglas R.W. Wylie. The accessory optic system contributes to the spatio-temporal tuning of motion-sensitive pretectal neurons. $J$ Neurophysiol 90: 1140-1151, 2003; 10.1152/jn.00653.2002. The nucleus of the basal optic root (nBOR) of the accessory optic system (AOS) and the pretectal nucleus lentiformis mesencephali (LM) are involved in the analysis of optic flow that results from self-motion and are important for oculomotor control. These neurons have large receptive fields and exhibit direction selectivity to large moving stimuli. In response to drifting sine wave gratings, $\mathrm{LM}$ and $\mathrm{nBOR}$ neurons are tuned to either low spatial/high temporal frequencies (SF, TF) or high $\mathrm{SF} /$ low $\mathrm{TF}$ stimuli. Given that velocity $=\mathrm{TF} / \mathrm{SF}$, these are referred to as "fast" and "slow" neurons, respectively. There is a heavy projection from the AOS to the pretectum, although its function is unknown. We recorded the directional and spatio-temporal tuning of LM units in pigeons before and after nBOR was inactivated by tetrodotoxin injection. After nBOR inactivation, changes in direction preference were observed for only one of $18 \mathrm{LM}$ units. In contrast, the spatiotemporal tuning of LM units was dramatically altered by nBOR inactivation. Two major effects were observed. First, in response to motion in the preferred direction, most $(82 \%)$ neurons showed a substantially reduced $(\mu=-67 \%$ ) excitation to low SF/high TF gratings. Second, in response to motion in the anti-preferred direction, most $(63 \%)$ neurons showed a dramatically reduced $(\mu=-78 \%)$ inhibition to high SF/low TF gratings. Thus the projection from the nBOR contributes to the spatio-temporal tuning rather than the directional tuning of LM neurons. We propose a descriptive model whereby LM receives inhibitory and excitatory input from "slow" and "fast" nBOR neurons, respectively.

\section{N T R O D U C T I O N}

Self-motion induces patterns of optic flow across the retina (Gibson 1954). The pretectum and accessory optic system (AOS) work together to analyze optic flow and generate the optokinetic response (OKR) to facilitate retinal image stabilization (Grasse and Cynader 1990; Simpson 1984; Simpson et al., 1988). Retinal image stabilization ensures optimal visual acuity (Carpenter 1977; Westheimer and McKee 1973) and velocity discrimination (Nakayama 1981).

The AOS and pretectum are highly conserved in vertebrates. The mammalian pretectal nucleus of the optic tract (NOT) is homologous to the nucleus lentiformis mesencephali (LM) in birds, whereas the avian nucleus of the basal optic root (nBOR) of the AOS is homologous to the medial and lateral terminal nuclei (MTN, LTN) of the mammalian AOS (Fite 1985; Mc-

Address for reprint requests: D.R.W. Wylie, Department of Psychology, University of Alberta, Edmonton, T6G 2E9, Alberta, Canada (E-mail: dwylle@ualberta.ca).
Kenna and Wallman 1985a; Simpson 1984; Simpson et al., 1988; Weber 1985). AOS and pretectal neurons have extremely large receptive fields and exhibit direction selectivity to large-field visual stimuli moving in the contralateral visual field. Most LM and NOT neurons prefer temporal-to-nasal (T-N) motion (NOT: Collewijn 1975a,b; Distler and Hoffmann 1993; Hoffmann and Distler 1989; Hoffmann et al., 1988; Hoffman and Schoppmann 1975, 1981; Ibbotson et al., 1994; Ilg and Hoffmann 1996; Mustari and Fuchs 1990; Volchan et al., 1989; Yakushin et al., 2000; LM: Fan et al., 1995; Fite et al., 1989; Katte and Hoffmann 1980; McKenna and Wallman 1985b; Winterson and Brauth 1985; Wylie and Crowder 2000; Wylie and Frost 1996). MTN and LTN neurons prefer upward or downward motion (Cooper and Magnin 1986; Grasse and Cynader 1982, 1984; Natal and Britto 1987; Soodak and Simpson 1988). nBOR neurons prefer upward, downward, or nasalto-temporal (N-T) motion (Burns and Wallman 1981; Gioanni et al. 1984; Morgan and Frost 1981; Rosenberg and Ariel 1990; Wylie and Frost 1990).

In response to drifting sine wave gratings, pretectal and AOS neurons exhibit tuning in the spatio-temporal domain. In the NOT of wallabies, Ibbotson et al. (1994) distinguished two groups of neurons: those that preferred high spatial frequencies (SFs) and low temporal frequencies (TFs) versus those that preferred low SFs and high TFs. Given that velocity $=$ TF/SF, these two groups were referred to as "slow" and "fast" neurons, respectively. Strikingly similar observations were found in the LM (Wylie and Crowder 2000) and nBOR of pigeons (Crowder and Wylie 2001).

There is a massive projection from the AOS to the pretectum (mammals: Baleydier et al., 1990; Blanks et al., 1982, 1995; Giolli et al., 1984, 1985a,b, 1992; Kato et al., 1995; Mustari et al., 1994 ; birds: Azevedo et al., 1983; Brecha et al., 1980; Wylie et al., 1997); however, the physiological significance of this projection has not been studied extensively (Baldo and Britto 1990; Gu et al., 2001; Hamassaki et al., 1988; Nogueira and Britto 1991; Schmidt et al., 1994, 1998; van der Togt and Schmidt 1994 ). In the present study we investigated the contributions of the nBOR-LM projection to the direction and spatio-temporal tuning of LM neurons by recording their responses before and after the nBOR was inactivated by injection of tetrodotoxin (TTX).

\footnotetext{
The costs of publication of this article were defrayed in part by the payment of page charges. The article must therefore be hereby marked "advertisement" in accordance with 18 U.S.C. Section 1734 solely to indicate this fact.
} 
METHODS

\section{Surgery and extracellular recording}

The methods employed conformed to the Guidelines established by the Canadian Council on Animal Care and were approved by the Biosciences Animal Welfare and Policy Committee at the University of Alberta. Details for anesthesia, extracellular recording, stimulus presentation, and data analysis were previously described by Wylie and Crowder (2000). Briefly, pigeons were anesthetized with a ketamine $(65 \mathrm{mg} / \mathrm{kg}) /$ xylazine $(8 \mathrm{mg} / \mathrm{kg})$ mixture (im) and supplemental doses were administered as necessary. Based on the pigeon stereotaxic atlas (Karten and Hodos 1967), sufficient bone and dura were removed to expose the brain and allow access to the nBOR and LM with vertical penetrations. Recordings were made with tungsten microelectrodes (2-5 M $\Omega$ impedance). The extracellular signal was amplified, filtered, displayed on an oscilloscope, and fed to a window discriminator. TTL pulses representing single spikes were fed to a 1401plus [Cambridge Electronic Designs (CED)] and peri-stimulus time histograms were constructed with Spike2 software (CED).

\section{Stimulus presentation}

After units in either the nBOR or LM were isolated, the direction preference and the approximate locations of the receptive field boundaries and hot-spot were qualitatively determined by moving a large $\left(90^{\circ} \times 90^{\circ}\right)$ handheld stimulus in various areas of the visual field. Directional tuning and spatio-temporal tuning were determined quantitatively with sine-wave gratings that were generated by a VSGThree graphics computer (Cambridge Research Designs, Cambridge, UK), and back-projected onto a tangent screen that was located $50 \mathrm{~cm}$ from the bird $\left(90^{\circ} \times 75^{\circ}\right)$. Direction tuning was tested using gratings of an effective SF and TF at $15^{\circ}$ or $22.5^{\circ}$ increments, whereas spatiotemporal tuning was tested using gratings of varying SF [0.03-2 cycles per deg (cpd)] and TF [0.03-6 cycles per s (Hz)] moving in the preferred and anti-preferred directions. Each sweep consisted of $4 \mathrm{~s}$ of motion in one direction, a 3-s pause, $4 \mathrm{~s}$ of motion in the opposite direction, followed by a 3-s pause. Firing rates were averaged over 3-5 sweeps. Contour plots of the mean firing rate in the spatiotemporal domain were made using Sigma Plot.

\section{General procedure}

The general procedure was as follows. 1) Locate the nBOR based on stereotaxic coordinates and extracellular recording, noting the dorsal extent of the nBOR. 2) Replace the recording electrode with an injection canula (30 gauge) filled with TTX (Sigma-Aldrich, St. Louis, MO) in phosphate-buffered saline $(\mathrm{pH}=7.4)$. The canula was positioned such that the tip was $100 \mu \mathrm{m}$ above the location of the dorsal-most responsive cell from the recording track. 3) Lower a recording microelectrode into the pretectum and characterize the direction and spatio-temporal tuning of an LM unit (see Stimulus presentation above). 4) Inject TTX into the $\mathrm{nBOR}$. The time course and maximum diameter of sodium-channel blockade after an injection of TTX in solution depend on the volume and concentration of TTX used, and have been shown to approximate that of the diffusion process from an instantaneous point source (Zhuravin and Bures 1991). In some experiments we used a rather large volume of TTX, $1-1.5 \mu \mathrm{l}$, but at a weak concentration of $2 \mathrm{ng} / \mu \mathrm{l}$. In other experiments we used a more conservative volume of $0.3-0.5 \mu \mathrm{l}$ but at a concentration of $10 \mathrm{ng} / \mu \mathrm{l}$, which is typically used to produce a pharmacological inactivation (Baldi et al., 1998; Bielavska and Roldan 1996; Gallo and Candido 1995; Rashidy-Pour et al., 1996a,b; Roldan and Bures 1994; Zhuravin and Bures 1991). [Note that approximately the same absolute amount (2-4 ng) of TTX was used for both types of injections.] 5) After 15 min, the response properties of the LM unit were tested again. In some cases, an electrolytic lesion was placed at the recording site by passing a current of $30 \mu \mathrm{A}$ for $8-10 \mathrm{~s}$ (electrode positive).
Histology

At the end of the recording session, the animals were given an overdose of sodium pentobarbitol $(100 \mathrm{mg} / \mathrm{kg})$ and immediately perfused with saline $(0.9 \%)$ followed by paraformaldehyde [ $4 \%$ in $0.1 \mathrm{M}$ phosphate buffer $\left.(\mathrm{PB}), 4^{\circ} \mathrm{C}\right]$. Brains were extracted, postfixed for $2-12 \mathrm{~h}$ (4\% paraformaldehyde, $20 \%$ sucrose in $0.1 \mathrm{M} \mathrm{PB}$ ), and cryoprotected in sucrose overnight ( $20 \%$ in $0.1 \mathrm{M} \mathrm{PB}$ ). Frozen sections ( $45 \mu \mathrm{m}$ thick in the coronal plane) through the LM and nBOR were collected. Sections were mounted onto gelatin chrome aluminum-coated slides and lightly counterstained with neutral red or cresyl violet. The tissue was then examined using light microscopy to confirm the locations of electrode tracks and electrolytic lesions in the $\mathrm{LM}$ and the canula tracks in the nBOR.

\section{RE S U L T S}

We examined the directional and spatio-temporal properties of 18 LM units, before and after the nBOR was inactivated with TTX. Twelve animals were injected with 1-1.5 $\mu$ l of low concentration TTX $(2 \mathrm{ng} / \mu \mathrm{l})$, and 6 with $0.3-0.5 \mu \mathrm{l}$ of high concentration TTX $(10 \mathrm{ng} / \mu \mathrm{l})$ (see Table 1$)$. The histology showed tissue damage caused by the canula tracks terminated above the dorsal border of $\mathrm{nBOR}$ or had penetrated a small distance into the nucleus (Fig. 1A), and electrode tracks were visible in the pretectum. In 8 cases, electrolytic marking lesions were made at the recording sites (Fig. $1 B$ ). All 8 lesions were found in LM: four each were found in the medial and lateral subnuclei (LMm, LMl; Gamlin and Cohen 1988b).

After isolating an LM unit, it took approximately $1 \mathrm{~h}$ to collect the pre-TTX data. On subsequent injection of TTX into the $\mathrm{nBOR}$, recording was maintained for up to $5 \mathrm{~h}$. As the effects of TTX begin to decay after as little as $2 \mathrm{~h}$ (Zhuravin and Bures 1991), we considered only the first $2 \mathrm{~h}$ after the TTX injection in our analyses. The activity of a given neuron before and after the TTX injection is referred to as "pre-TTX" and "post-TTX," respectively.

\section{"Normal" properties of LM units}

All 18 LM units were direction selective (Fig. 3). A unit's direction preference was assigned by calculating the maximum of the best cosine fit to the tuning curve. Eleven, 4, 1, and 1 LM units preferred forward (i.e., temporal to nasal), downward, backward, and upward motion, respectively (Fig. 2A, Table 1). The remaining unit was a bidirectional neuron, which showed excitation to both forward and backward motion (see Fig. 3D). The predominance of neurons preferring forward motion is consistent with previous studies of the pigeon LM $(\mathrm{Gu}$ et al. 2001; Winterson and Brauth 1985; Wylie and Crowder 2000; Wylie and Frost 1996).

All 18 units were tuned in the spatio-temporal domain. Contour plots were constructed where TF was on the ordinate, SF was on the abscissa, and firing rate (relative to the SR) was plotted on the $z$-axis. Because motion in the preferred and anti-preferred directions generally results in excitation and inhibition of the neuronal firing, respectively, we refer to excitatory and inhibitory response plots (ER plots, IR plots) (e.g., Figs. 4 and 5). Some units showed a single maximum in the contour plot (e.g., Fig. 4A) but two peaks was more common (e.g., Figs. 4B, 5A-D). Based on the method of Perrone and Thiele (2001) the locations of the peaks in the contour plots were assigned quantitatively by fitting each peak 
TABLE 1. Effect of inactivation of nucleus of the basal optic root on direction and spatio-temporal tuning of units in the lentiformis mesencephali

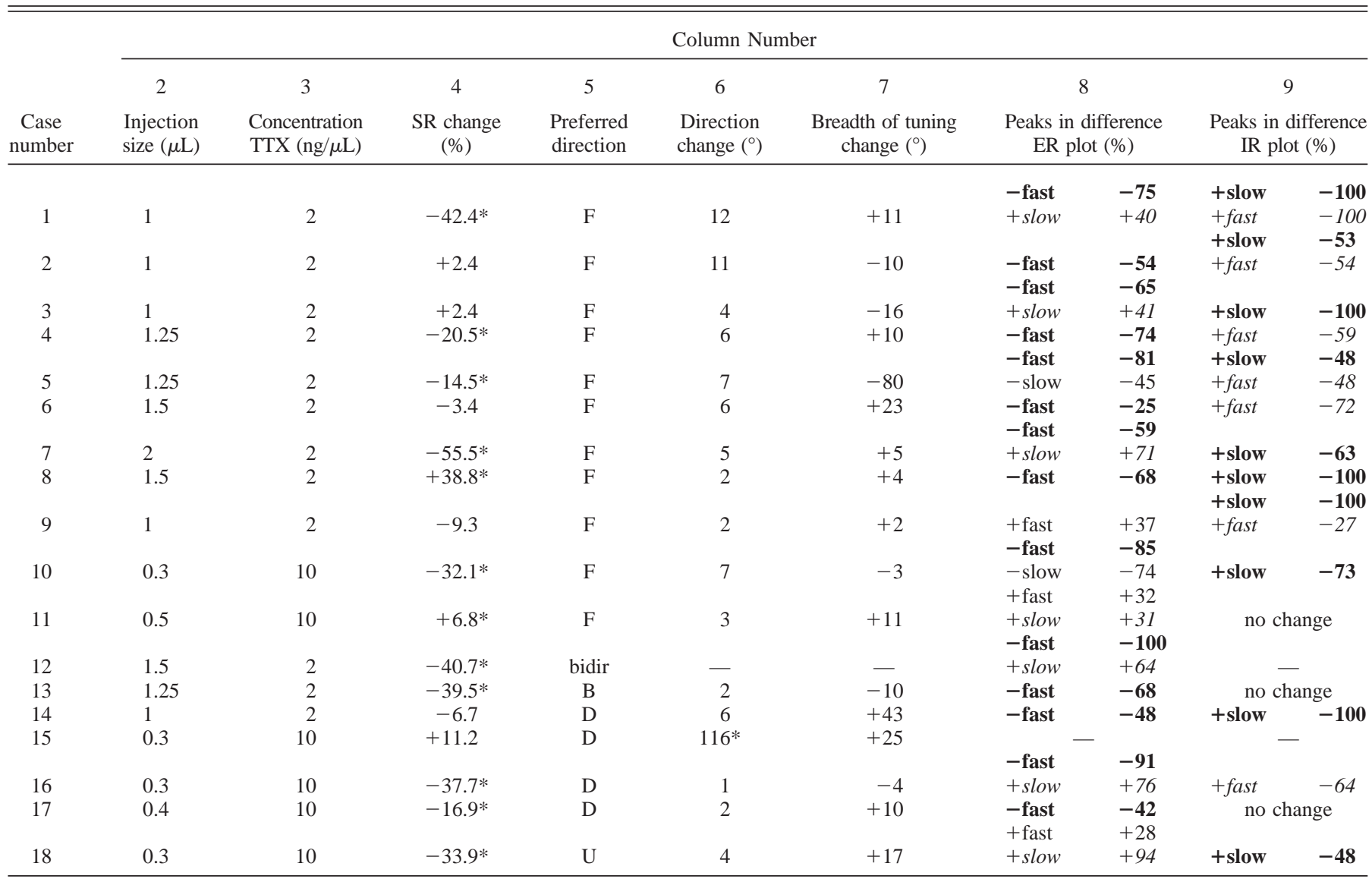

Details from each of the 18 cases are summarized. For spontaneous rate (SR) and breadth of tuning change, negative numbers indicate a reduction post-TTX and * indicates statistical significance. F, B, U, and D = forward (temporal to nasal), backward (nasal to temporal), upward, and downward motion, respectively. bidir = bidirectional neuron. In columns eight and nine, respectively, the peaks in the difference excitatory and inhibitory response (ER, IR) plots are given. "-fast," for example, indicates that there was a negative in the difference plot. Magnitudes of the peaks are also tabulated. See Results for additional details.

to a two-dimensional Gaussian function: $\mathrm{G}^{\prime}(\mathrm{u}, \omega)=$ $\left\{\exp \left[-\left(\mathrm{u}^{\prime}\right)^{2} / \sigma_{\mathrm{x}}{ }^{2}\right]\right\} \times\left[-\left(\omega^{\prime}\right)^{2} / \sigma_{\mathrm{y}}{ }^{2}\right]+\mathrm{P}$, where $\mathrm{u}^{\prime}=(\mathrm{u}-\mathrm{x})$ $\cos \theta+(\omega-\mathrm{y}) \sin \theta$ and $\omega^{\prime}=-(\mathrm{u}-\mathrm{x}) \sin \theta+(\omega-\mathrm{y})$ $\cos \theta$, and where $\mathrm{u}$ is the Ln SF of the test grating, $\omega$ is the Ln TF of the test grating, $\theta$ is the angle of the Gaussian, $(x, y)$ is the location of the peak of the Gaussian (in $u$ and $\omega$ coordinates), and $\sigma_{\mathrm{x}}$ and $\sigma_{\mathrm{y}}$ are the spread of the Gaussian in the $\mathrm{u}^{\prime}$ and $\omega^{\prime}$ dimensions, respectively. The $\mathrm{G}$ values were normalized, and added to a constant $(\mathrm{P})$. The values $\sigma_{\mathrm{x}}, \sigma_{\mathrm{y}}, \mathrm{x}, \mathrm{y}$, and $\mathrm{P}$ were optimized to minimize the sum of the mean error between the real and $G$ values using the solver function in Microsoft Excel. In Fig. $2 B$ the locations of the primary peaks from the ER plots are shown. Consistent with previous studies of the pretectum (Ibbotson et al., 1994; Wylie and Crowder 2000), the peaks cluster into two quadrants: units responding best to gratings of low SF/high TF (11 cells) or high SF/low TF (7 cells). Following Ibbotson et al. (1994) we refer to these as "fast" and "slow" cells, respectively.

\section{Changes in spontaneous rate of LM units after $n B O R$ inactivation}

Table 1 shows the percentage change in the spontaneous rates (SR) of LM units after nBOR inactivation f for decreases,
$\%$ change $=[($ post-TTX - pre-TTX $) /$ pre-TTX $] \times 100$; for increases, $=[($ post-TTX - pre-TTX $) /$ post-TTX $] \times 100\}$. For 11 cases there was a significant decrease in SR (15-56\%), whereas 2 cases showed a significant increase (7 and 39\%) ( $t$-test, $P<0.0028$; Bonferroni correction for multiple comparisons), and 5 cases showed no significant change. The average change in SR across all 18 cases was $-16.2 \%$.

\section{Effects of $n B O R$ inactivation on the direction tuning of LM units}

Figure 3 shows the direction tuning curves for 6 LM units, pre-TTX (solid line) and post-TTX (broken line). Only one unit (Fig. $3 F$ ) showed a substantial change in direction preference $\left(116^{\circ}\right)$. For the other units, the direction change did not exceed $12^{\circ}\left(\right.$ mean $\left.=5^{\circ}\right)($ see Table 1$)$.

From Fig. 3 it is apparent that the breadth of tuning changed for some LM units. Typically, the half-power [(maximal excitation $-\mathrm{SR}$ )/2] is used to quantify the breadth of excitation. The half-power bandwidth was determined by measuring the angle from the origin to the two points where the tuning curve intersected the half-power value. (This type of analysis was not appropriate for the bidirectional unit.) For example, the breadth of tuning increased for the unit in Fig. $3 E\left(43^{\circ}\right)$, and decreased 
A

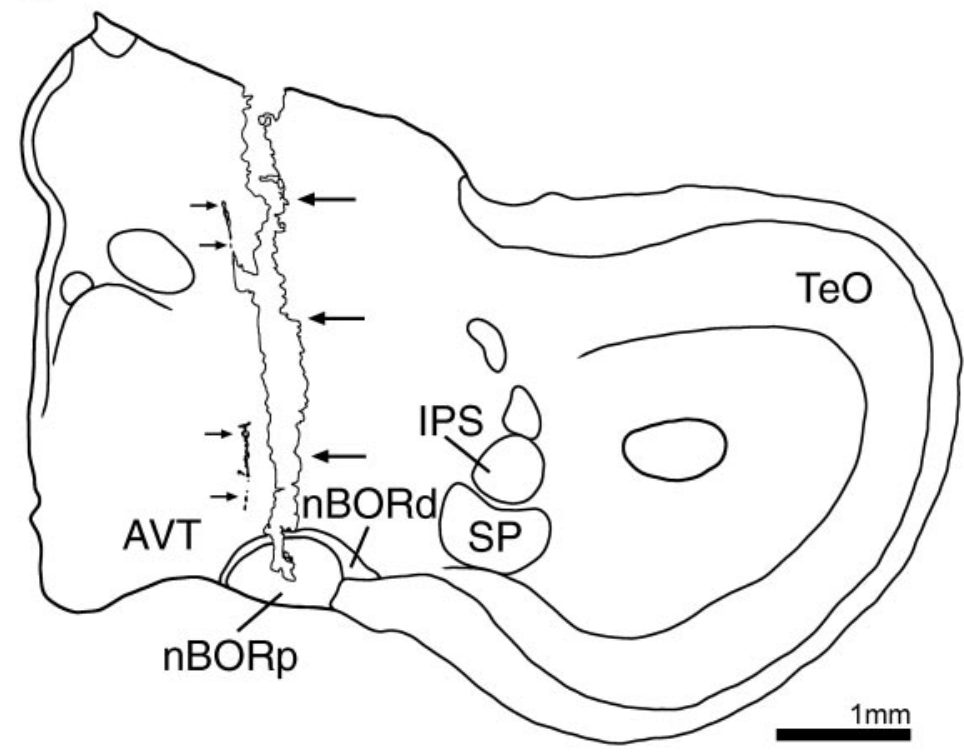

B

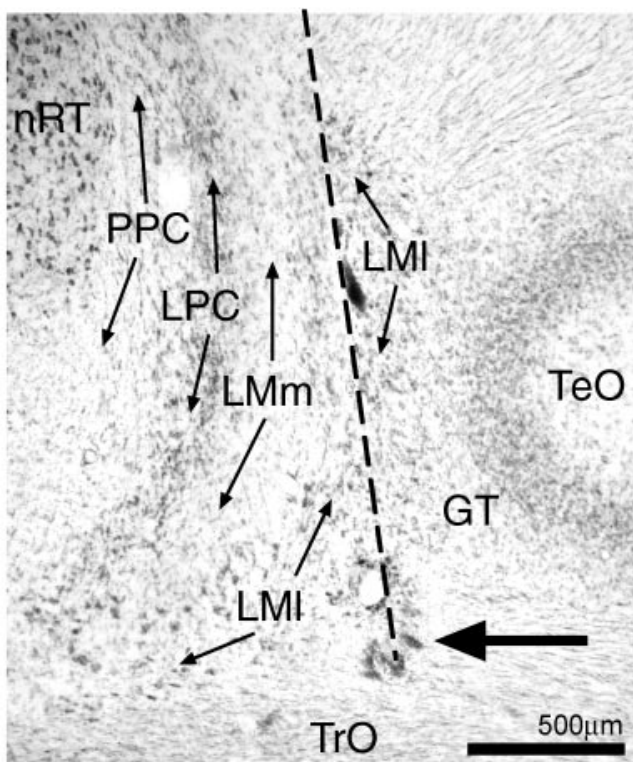

FIG. 1. Histology. A: camera lucida tracing of coronal section through the mesencephalon, highlighting locations of electrode track (small arrows) and canula track (large arrows) into the nucleus of basal optic root (nBOR). nBOR is divided into nBOR proper (nBORp) and nBOR pars dorsalis (nBORd). B: photomicrograph of coronal section through the pretectum, indicating location of electrode track (dashed line) and marking lesion (large arrow) in nucleus lentiformis mesencephali (LM). The nomenclature of Gamlin and Cohen (1988b) is used. The LM consists of medial and lateral subnuclei (LMm, LMl). LMm is bordered medially by the nucleus laminaris precommisuralis (LPC). The nucleus principalis precommisuralis (PPC) resides between LPC and nucleus rotundus (nRt). AVT, area ventralis of Tsai; GT, tectal gray; IPS, nucleus interstitio-pretecto-subpretectalis; SP, nucleus subpretectalis; TeO, optic tectum; TrO, tractus opticus. Scale bars; $1 \mathrm{~mm}$ in $A, 500 \mu \mathrm{m}$ in $B$.

for the unit in Fig. $3 A\left(-16^{\circ}\right)$. Four units showed an increase in the half-power bandwidth of $\geq 15^{\circ}$ (post-TTX - pre-TTX), whereas 2 units showed a decrease of $\geq 15^{\circ}$ (see Table 1).

The magnitude of modulation, both excitation and inhibition, was altered for some units (e.g., Fig. 3B). The \%change in the magnitude of excitation and inhibition was calculated from the tuning curves for each unit. Across all 18 cases, there was an average decrease in the magnitude of excitation post-TTX of $-17.3 \%$, which was significantly different from zero (single sample $t$-test, $P<0.02$ ). With respect to the magnitude of inhibition, a more dramatic and consistent pattern was observed. Averaged across 16 cases (i.e., excluding the units in Fig. 3, $D$ and $F$ ), the magnitude of inhibition decreased by $-36.1 \%$, which was significantly different from zero (single sample $t$-test, $P<0.002$ ).

\section{Spatio-temporal changes after nBOR inactivation}

The spatio-temporal properties were examined pre-TTX for all 18 units, and for all but one unit post-TTX (case \#15). The bidirectional cell did not have an IR plot. Thus we obtained pre- and post-TTX ER plots for 17 cells and pre- and post-TTX IR plots for 16 cells. The inactivation of the nBOR affected the spatio-temporal profiles of all LM units tested.

In Fig. 4 data from case \#3 are shown. Pre-TTX and postTTX ER and IR plots are shown in $A$ and $B$, respectively. In these plots the SR is represented by the solid black fill, and excitation and inhibition are represented by red and green, respectively. The stronger the degree of excitation/inhibition, the progressively brighter and less saturated the red/green fill. Thus the peak excitation and inhibition appear off-white. In addition, "difference" plots are shown. These were calculated by subtracting the pre-TTX plot from the post-TTX plot. On the difference plots, solid black fill indicates no change pre- to post-TTX, blue represents negative values or a lower firing rate post-TTX, and yellow represents positive values or a greater firing rate post-TTX. For the cell shown in Fig. 4, with respect to the ER plots (Fig. 4A), pre-TTX there was a single excitatory peak at $1 \mathrm{cpd} / 1 \mathrm{~Hz}$. Post-TTX, although unchanged in magnitude, the peak was shifted lower on the TF scale. The difference ER plot had a negative peak in the fast region, reflecting the fact that the unit was less responsive to fast stimuli. Note also the positive peak in the difference ER plot at high SFs and low TFs, indicating that the cell showed an increased excitation to these gratings and corroborating the fact that the peak shifted to lower TFs. With respect to motion in the anti-preferred direction (IR plots, Fig. 4B), pre-TTX this unit had a major inhibitory peak at $1 \mathrm{cpd} / 0.5 \mathrm{~Hz}$, and very small secondary peak (-5 spikes/s) at $0.03 \mathrm{cpd} / 2 \mathrm{~Hz}$. Post-TTX, the secondary peak remained, but the peak in the slow region was virtually eliminated. In fact, post-TTX the cell was excited in response to high SF stimuli at the lowest TF drifting in the anti-preferred direction (+25 spikes/s). The difference IR plot had a positive peak in the slow region, reflecting the loss of the inhibitory response and the appearance of the excitatory response to high $\mathrm{SF} /$ low TF gratings post-TTX.

In Fig. $4 C$, peri-stimulus time histograms (PSTHs) to three different SF/TF combinations are shown. Three sweeps preTTX and 3 sweeps post-TTX are shown, and the approximate time at which the PSTHs were collected relative to the TTX injection is provided. These data indicate the reliability of the effects we observed. To $0.6 \mathrm{cpd} / 2 \mathrm{~Hz}$ gratings (top), the excitation to motion in the preferred direction was clearly reduced 

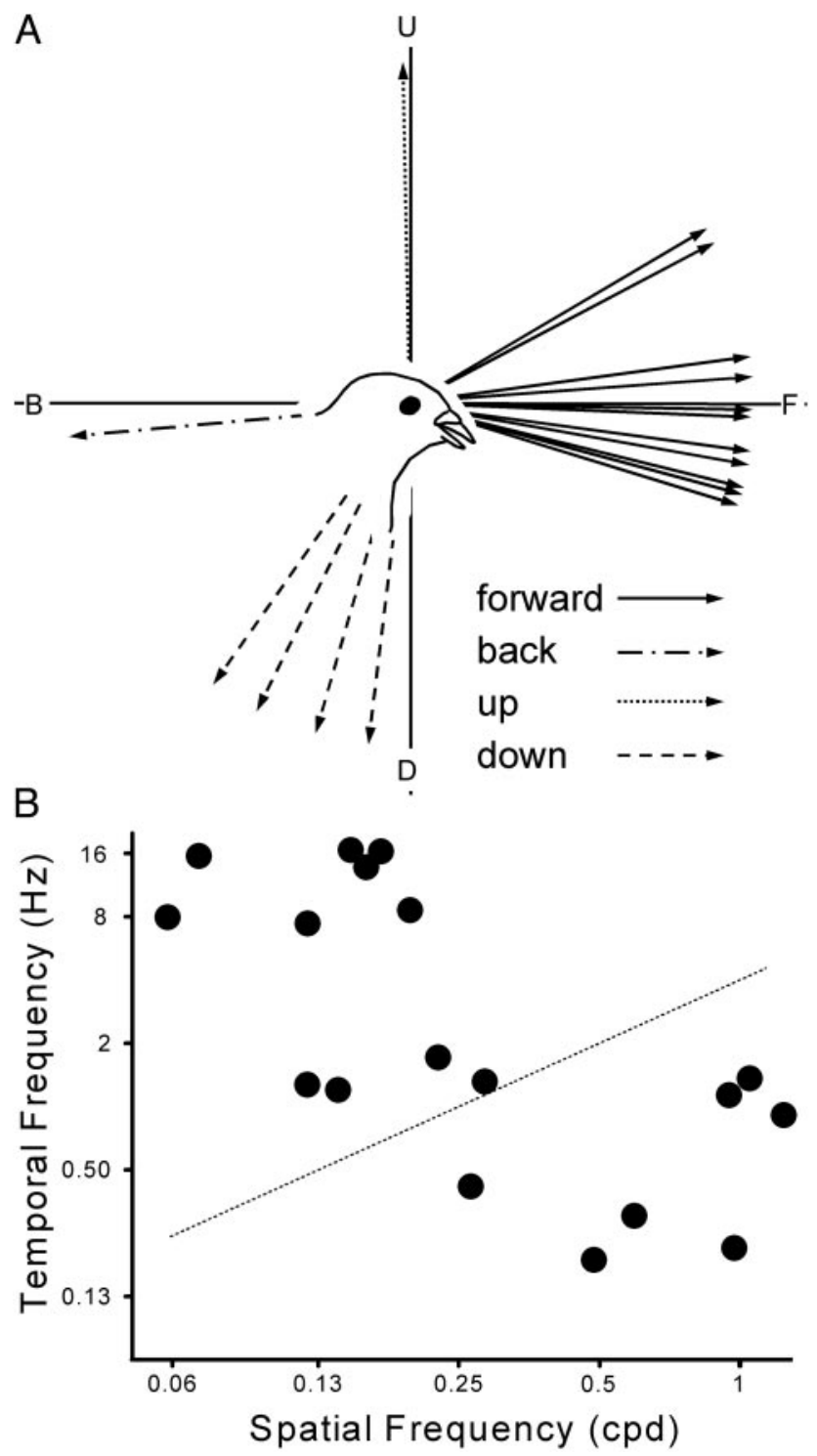

FIG. 2. Directional and spatio-temporal tuning of LM units. A: each arrow represents preferred direction for each unit, as calculated from peak of best-fit cosine to direction tuning curve. $\mathrm{U}, \mathrm{B}, \mathrm{D}$, and $\mathrm{F}$ represent up, back (nasal to temporal), down, and forward (temporal to nasal) motion. $B$ : filled circles represent locations of primary peaks from excitatory response (ER) contour plots. Dashed diagonal line represents stimulus velocity of $4 \%$, which Ibbotson and Price (2001) used to distinguish "fast" and "slow" groups in both wallaby nucleus of the optic tract (NOT) and pigeon LM.

post-TTX. To $0.5 \mathrm{cpd} / 0.13 \mathrm{~Hz}$ gratings (middle) there was an increased response to motion in the preferred direction postTTX, and the inhibition to motion in the anti-preferred direction seen pre-TTX was absent. In fact, post-TTX this unit was excited in response to this grating drifting in the anti-preferred direction. To $0.5 \mathrm{cpd} / 0.5 \mathrm{~Hz}$ gratings (bottom) the excitation to motion in the preferred direction was unchanged post-TTX, but the strong inhibition to motion in the anti-preferred direction was absent.

The directional tuning curves for this case, shown in Fig. $3 A$, were established with $0.5 \mathrm{cpd} / 0.5 \mathrm{~Hz}$ gratings. Consistent with the data in Fig. 4, there was no change in the magnitude of excitation to motion in the preferred direction post-TTX, but the inhibition to motion in the anti-preferred direction was abolished. Clearly, the change in the depth of modulation preto post-TTX observed in the direction tuning curves was dependent on the SF/TF combination used. For case \#3, if we had used $0.06 \mathrm{cpd} / 2 \mathrm{~Hz}$ gratings we would have observed a decrease in the magnitude of excitation. Likewise, if we had used $0.5 \mathrm{cpd} / 0.13 \mathrm{~Hz}$ gratings we would have observed an increase in the magnitude of excitation.

\section{Changes in the ER plots after nBOR inactivation}

Figure 5, $A$ and $B$, shows the effects of nBOR inactivation on the ER plots of two other LM units. The unit in Fig. 5A (case \#10) showed two excitatory peaks in the pre-TTX ER plot (primary, $1 \mathrm{cpd} / 2 \mathrm{~Hz}$; secondary, $0.06 \mathrm{cpd} / 16 \mathrm{~Hz}$ ). Post-TTX the peak in the fast region was absent, but the peak in the slow region was unaffected. The difference ER plot showed a negative peak in the fast region, and a smaller positive peak to the lowest TFs. The unit in Fig. 5B (case \#8) had two excitatory peaks in the fast region pre-TTX (primary, $0.125 \mathrm{cpd} / 0.5 \mathrm{~Hz}$; secondary, $0.125 \mathrm{cpd} / 16 \mathrm{~Hz}$ ). Post-TTX the primary peak is present, although at less than half the size, and the peak at 16 $\mathrm{Hz}$ disappeared. In addition, a second peak appeared in the slow region $(0.5 \mathrm{cpd} / 0.5 \mathrm{~Hz})$.

All three examples (Figs. 4A, 5, $A$ and $B$ ) are quite similar in that the difference ER plots had negative peaks in the fast region, indicating that LM units showed less excitation to low $\mathrm{SF} /$ high TF stimuli moving in the preferred direction postTTX. This was the most common and dramatic effect that we observed in the ER plots. In column eight of Table 1 the presence of peaks in the difference ER plots for all 17 units tested is noted. Negative fast peaks ( - fast) and positive slow peaks $(+$ slow) are shown in bold and italics, respectively. In addition, the magnitude of the peak is indicated as the \%change for that SF/TF combination [for - ve peaks, \%change $=$ (postTTX - pre-TTX)/pre-TTX; for +ve peaks, $=($ post-TTX pre-TTX)/post-TTX $\times 100$ ]. Of the 17 units tested, 14 had a negative peak in the fast region of the difference ER plots. For these 14 cells, there were four cases in which an excitatory peak in the fast region of the pre-TTX ER plot was virtually eliminated post-TTX (as in Fig. 5A). The average magnitude of these 14 peaks was $-67 \%$. For 7 cells there was a positive peak in the slow region of the difference ER plots (e.g., Fig. $4 A$ ) and the average magnitude was $+61 \%$.

In Fig. 6A, the ER plots are averaged across all 17 cells. The responses for each cell were first normalized, using a common scale for the pre-TTX and post-TTX plots. Despite the averaging, two excitatory peaks were apparent pre-TTX, reflecting the spatio-temporal preferences of the fast and slow cells. Post-TTX both peaks were reduced in size, particularly the fast peak, and at the higher TFs. For the difference ER plot, based on the pooled variance of the associated with all points in the plot, values above 0.16 (and below -0.16) are statistically significant $(P<0.05)$. [The critical difference $(\mathrm{CD})$ was calculated as follows: $C D=\mathrm{t}_{\text {crit }} \times \sqrt{\text { pooled variance } / n}$.] The difference ER plot had a negative peak in the fast region, which was largest in magnitude $(-0.39)$ at $0.13 \mathrm{cpd} / 8 \mathrm{~Hz}(P<0.002$, single-sample $t$-test). The positive peak (0.13) in the region of the highest SFs and lowest TFs was not significantly different from zero. 

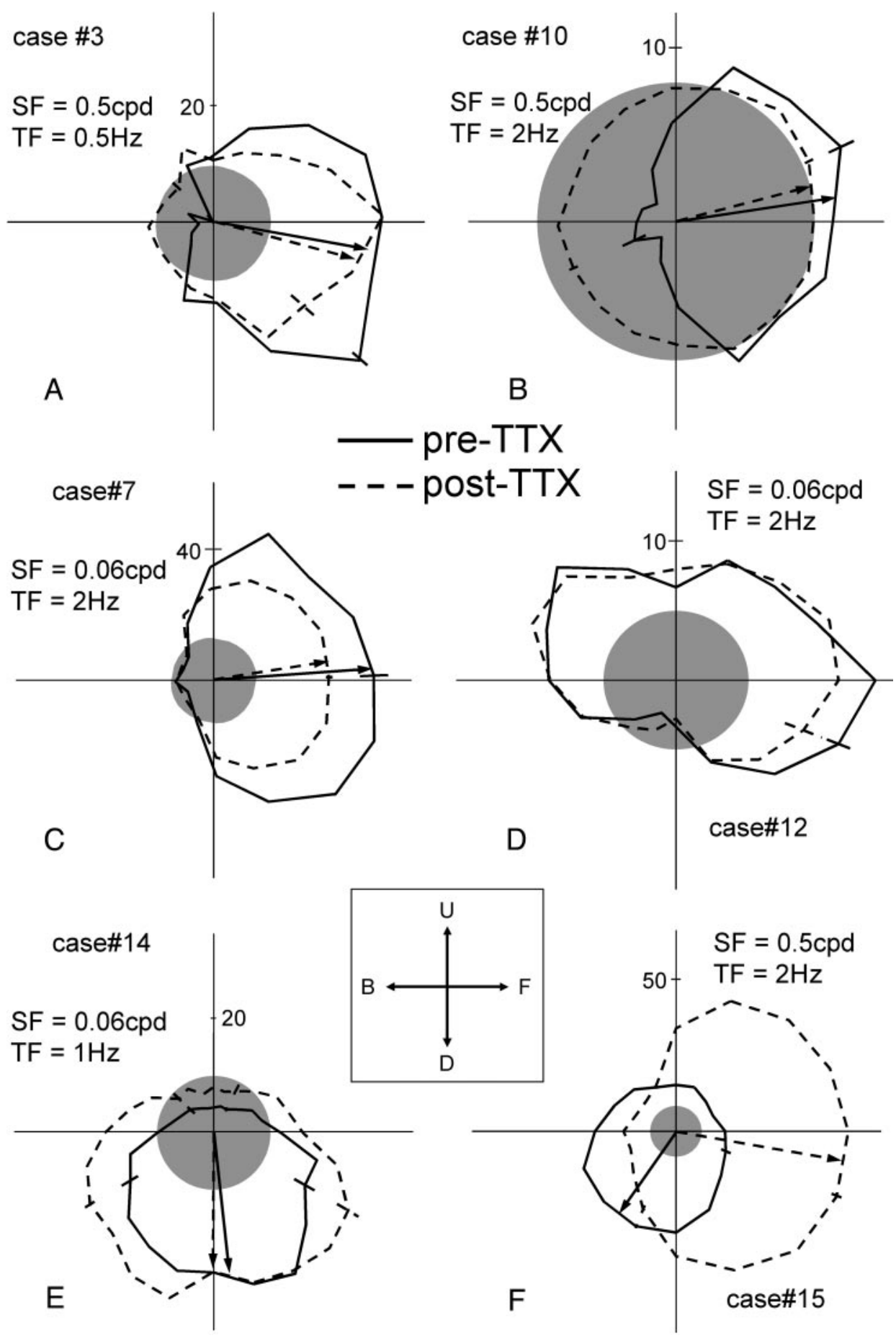

FIG. 3. Directional tuning of LM units pretetrodotoxin (TTX) and post-TTX. Polar plots illustrating directional tuning of units in LM before and after nBOR was injected with TTX (pre-TTX, solid line; post-TTX, dashed line). Firing rate (spikes/s) relative to the spontaneous rate (SR; gray circle) is plotted as a function of direction of motion in polar coordinates (i.e., the SR has been set to zero; outside the gray circle $=$ excitation, inside $=$ inhibition). Solid and dashed arrows represent the unit's preferred direction pre-TTX and post-TTX, respectively, as calculated from best-fit cosines to tuning curves. [A cosine could not be fit to the tuning curves for the bidirectional unit $(D)]$. Spatial and temporal frequencies (SF and TF, respectively) of gratings used for directional tuning are illustrated for each case. $\mathrm{U}, \mathrm{B}, \mathrm{D}$, and $\mathrm{F}$ represent up, back (nasal to temporal), down, and forward (temporal to nasal) motion.

\section{Changes in the IR plots after nBOR inactivation}

Figure 5, $C$ and $D$, shows pre-TTX and post-TTX IR plots for two other LM units. The unit in Fig. $5 C$ showed a large inhibitory peak in the slow region pre-TTX $(1 \mathrm{cpd} / 2 \mathrm{~Hz})$, with a secondary peak in the fast region. Post-TTX the primary peak was eliminated, leaving a peak in the fast region $(0.06 \mathrm{cpd} / 2$ $\mathrm{Hz}$ ). The cell in Fig. 5D also had two inhibitory peaks pre-TTX (primary, $0.06 \mathrm{cpd} / 8 \mathrm{~Hz}$; secondary, $0.5 \mathrm{cpd} / 2 \mathrm{~Hz}$ ). Post-TTX, both peaks were reduced in magnitude.

For the 16 cells tested, the most common effect of the TTX injection on the IR plots was a decrease in the amount of inhibition in the slow and/or fast regions post-TTX. This was manifested as positive peaks in the slow and/or fast regions in the difference IR plots. The effect on the slow region was more consistent and more dramatic. In 3 cases an inhibitory peak in the slow region was eliminated post-TTX (as in Fig. $4 B$ ). Of the 16 difference IR plots, 10 (63\%) had positive peaks in the slow region (as in Figs. $4 B, 5 C$ ) with an average magnitude of $-78 \%$. Seven difference IR plots had positive peaks in the fast region with an average magnitude of $-60 \%$.

The averaged normalized IR plots are shown in Fig. $6 B$. Note that post-TTX there is a reduction in the magnitude of 

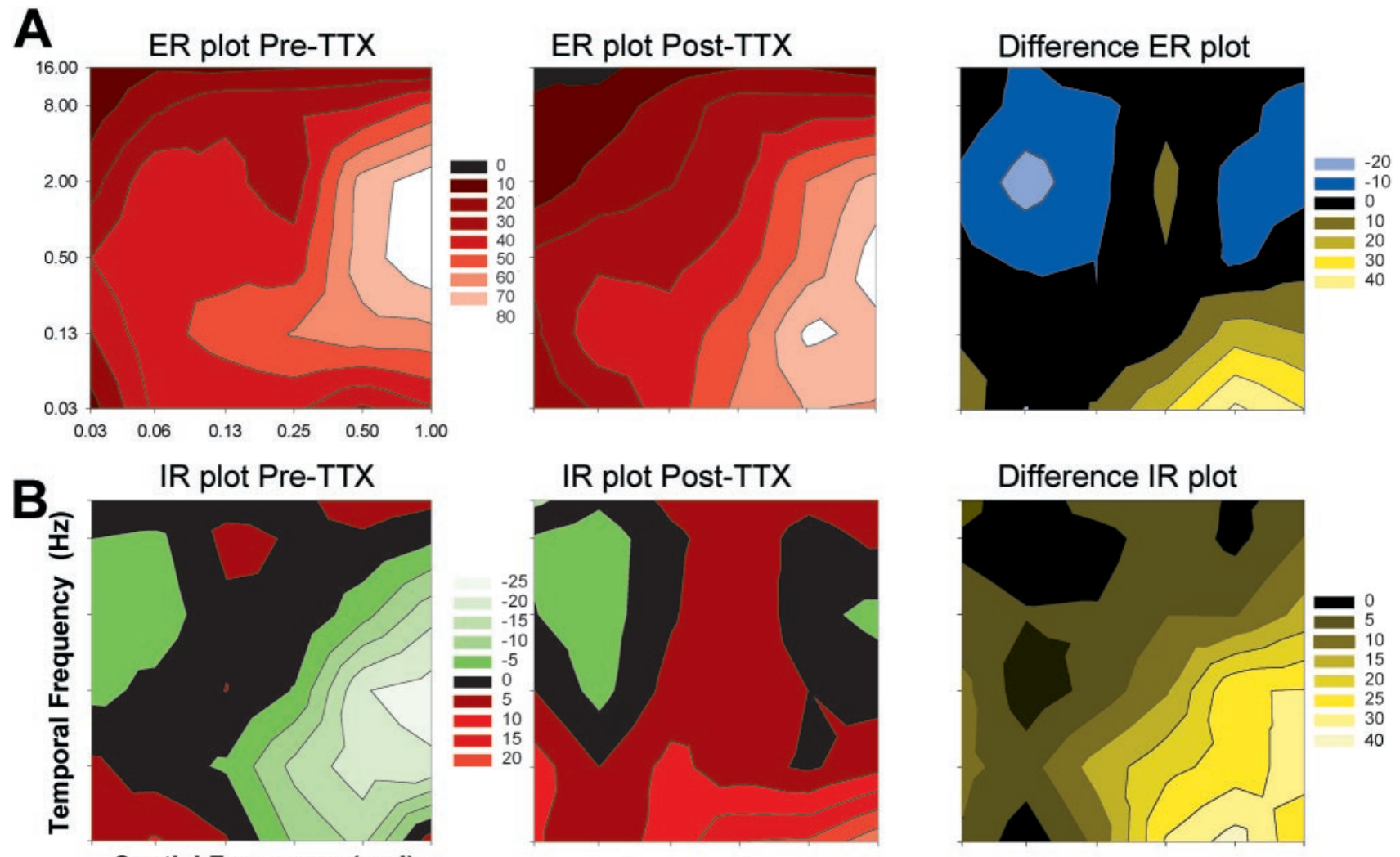

Spatial Frequency (cpd)

case \#3

C

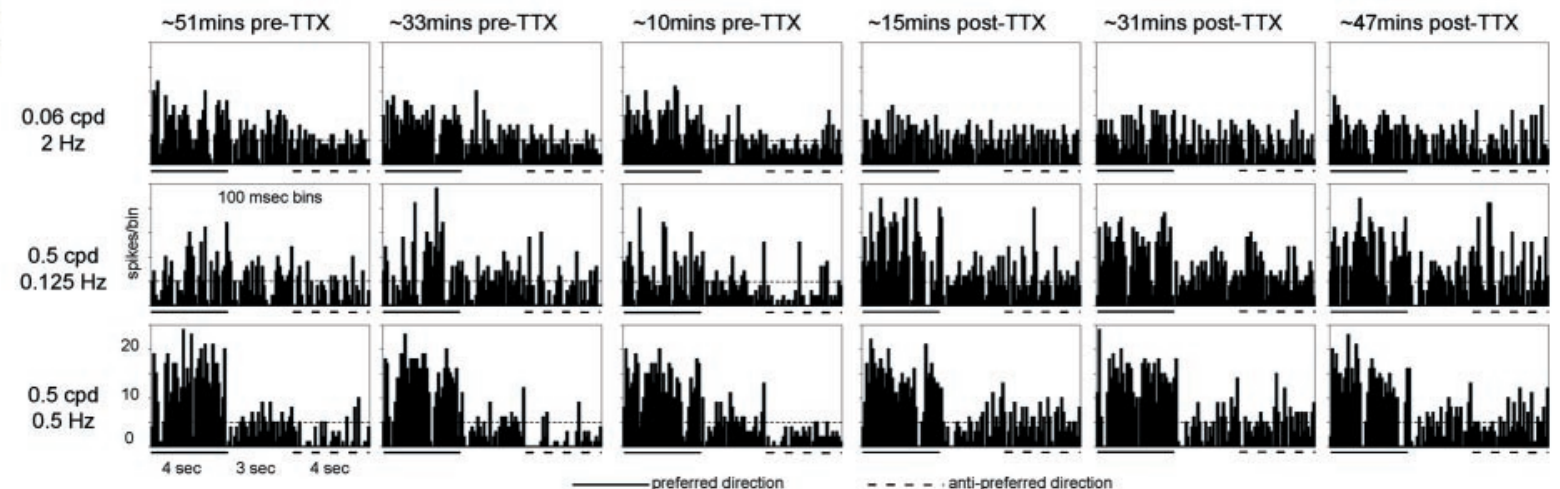

FIG. 4. Effects of inactivation of nBOR on the spatio-temporal tuning of LM unit. Data from case \#3 are shown. $A$ and $B$ : contour plots of responses to gratings of varying temporal and spatial frequencies (SF, TF), respectively, drifting in the preferred direction (ER plots) and anti-preferred direction (IR plots) are shown. SF and TF are plotted on the abscissa and ordinate, respectively. Left: Pre-TTX plot; middle: post-TTX plot; and right: difference (post-TTX - pre-TTX) plot. Pre-TTX and post-TTX contour plots use a common scale to represent firing rate (spikes/s) above (+; reds) or below ( - ; greens) spontaneous rate (black). These scales are shown between the pre-TTX and post-TTX columns. Scale for the difference plot is shown on far right. Black represents a value of zero; i.e., no change in response pre- to post-TTX; blues represent negative values, i.e., lower firing rate post-TTX; and yellows represent positive values, i.e., higher firing rate post-TTX. Progressively brighter and less saturated colors indicate progressively larger magnitudes in contour plots. $C$ : series of peri-stimulus time histograms (PSTHs) of individual sweeps of responses to three different SF/TF combinations. Three sweeps pre-TTX and three sweeps post-TTX are shown, and the approximate time relative to TTX injection is shown. Each sweep consisted of 4-s motion in preferred direction, followed by 3-s pause, followed by 4-s motion in anti-preferred direction. Dotted lines in PSTHs represent spontaneous rate.

inhibition to gratings throughout much of the spatio-temporal domain, although it is particularly dramatic to the high $\mathrm{SF} /$ low TF gratings. For the difference IR plot, values above 0.17 (and below -0.17$)$ are statistically significant $(P<$ $0.05)$. The difference plot had a large positive peak $(0.5)$ in the slow region at $0.5 \mathrm{cpd} / 0.5 \mathrm{~Hz}(P<0.0004$, singlesample $t$-test).

\section{I S C U S S I O N}

In the present study we sought to determine the function of the projection from the AOS to the pretectum (Azevedo et al., 1983; Baleydier et al., 1990; Blanks et al., 1982, 1995; Brecha et al., 1980; Giolli et al., 1984, 1985a, 1992; Kato et al., 1995; Mustari et al., 1994; Schmidt et al., 1998; Wylie et al., 1997) by observing the directional and spatio- 

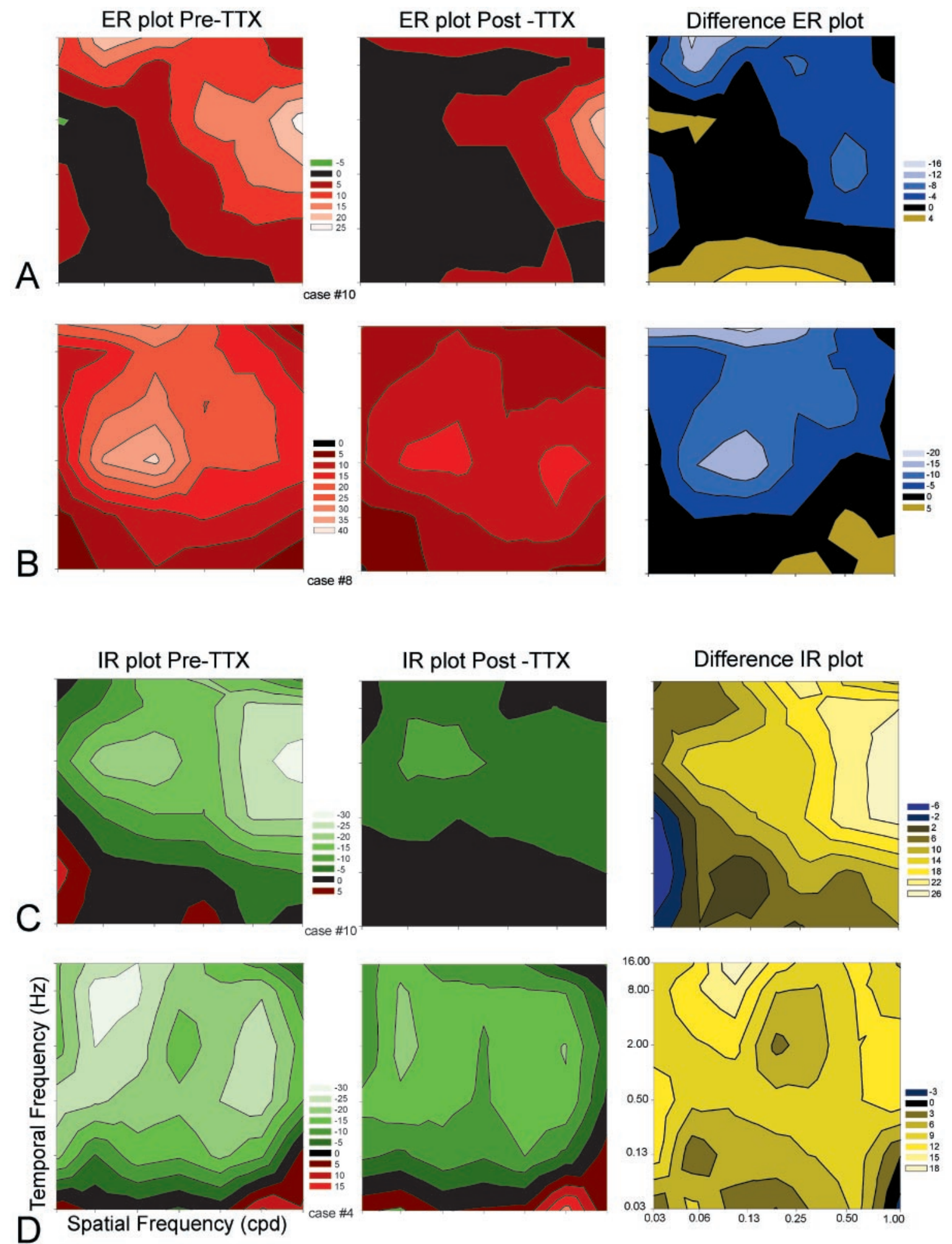

FIG. 5. Effects of inactivation of nBOR on the spatio-temporal tuning of LM units. Spatio-temporal tuning of LM units to gratings drifting in preferred (ER plots, $A$ and $B$ ) and anti-preferred directions (IR plots, $C$ and $D$ ) before and after nBOR was injected with TTX (pre-TTX, post-TTX). Note that $A$ and $C$ are from the same case. See caption to Fig. 4 for additional details.

temporal tuning of LM units before and after inactivation of the nBOR with TTX. We found that, although the effects on the directional tuning were minor, the spatiotemporal properties of all LM units changed after nBOR inactivation.
Changes in the directional tuning of LM neurons after $n B O R$ inactivation

In the present study we found that the direction preference of LM units was rarely altered post-TTX. In some cases the 

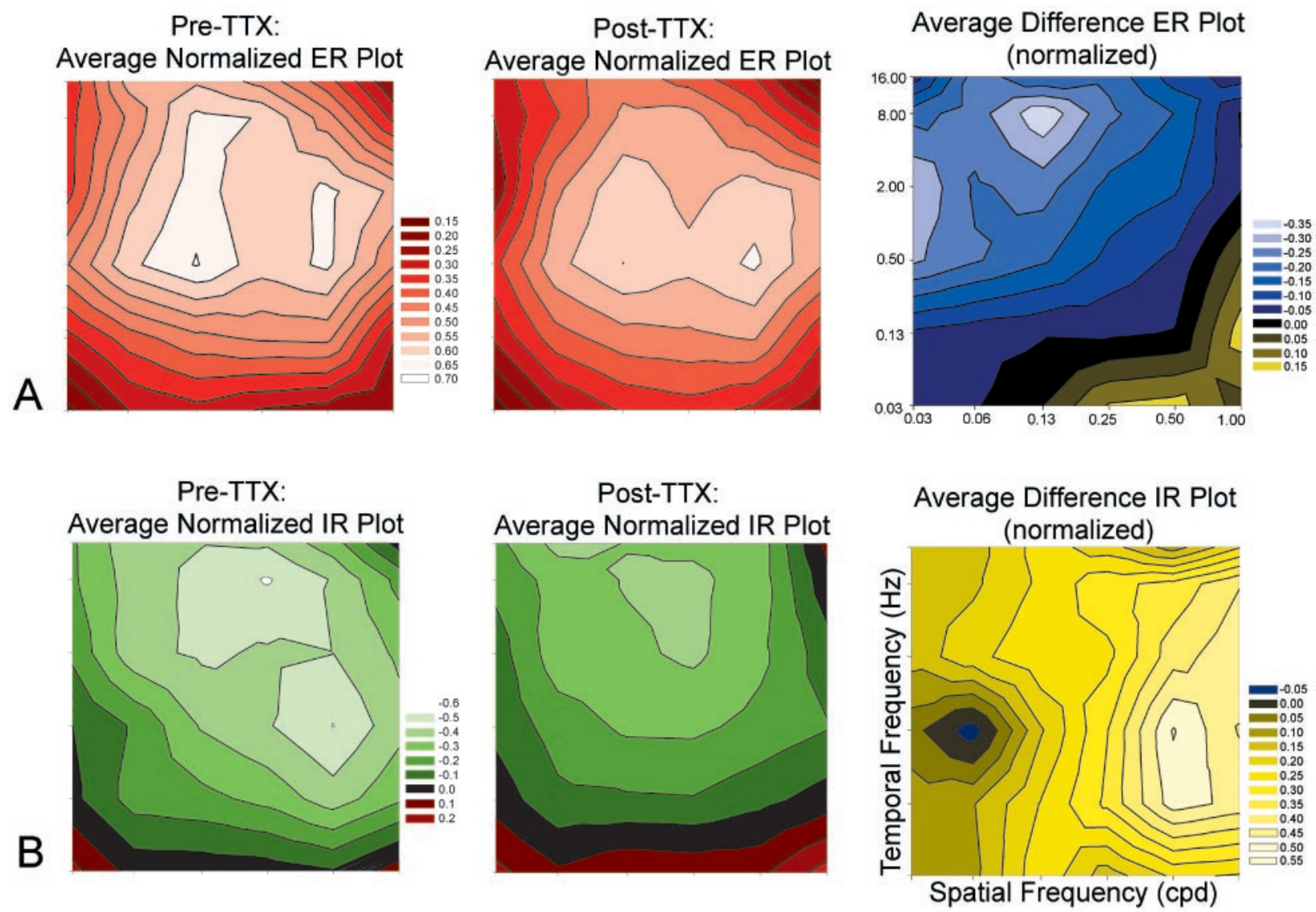

FIG. 6. Effects of inactivation of nBOR on the spatio-temporal tuning of LM units to gratings drifting in preferred (ER plots, $A$ ) and anti-preferred directions (IR plots, $B$ ). Normalized data averaged across all cases are shown. See caption to Fig. 4 and Results for additional details.

breadth of the tuning was altered, as was the depth of modulation. Gu et al. (2001) examined the directional tuning of LM neurons before and after the $\mathrm{nBOR}$ was temporarily inactivated by lidocaine. However, they used moving bars as stimuli, which are not as appropriate as large-field stimuli (Frost 1985). Nonetheless, with respect to the directional tuning of LM neurons, the results of the present study are in agreement with those of Gu et al. (2001). They found that the inactivation of the nBOR altered the breadth and depth of tuning, but not the direction preferences of LM neurons. Gu et al. (2001) used extremely small volumes of lidocaine and it is unlikely that there was any spread outside the nBOR. Given that we had similar observations with respect to directional tuning of LM neurons, we are confident that our observations are not attributable to the possibility that the TTX spread beyond the nBOR.

\section{Changes in spatio-temporal preferences of LM neurons after $n B O R$ inactivation}

This study is the first to demonstrate that the spatio-temporal properties of LM neurons are affected by the activity of other nuclei in the optokinetic system. That pretectal neurons are tuned in the spatio-temporal domain was first shown in the wallaby NOT (Ibbotson et al., 1994; Ibbotson and Price 2001). Two groups of neurons were found: "fast" neurons preferred low SF/high TF gratings, whereas "slow" neurons preferred high SF/low TF gratings. Subsequently we found such fast and slow neurons in the pigeon LM and the nBOR (Wylie and
Crowder 2000; Crowder and Wylie 2001). In the present study we found that $\mathrm{nBOR}$ inactivation changed the spatio-temporal tuning of LM units. With respect to stimuli drifting in the preferred direction, after $\mathrm{nBOR}$ inactivation, most LM units showed less excitation to low $\mathrm{SF} /$ high $\mathrm{TF}$ (i.e., fast) gratings and some units showed more excitation to high SF/low TF (i.e., slow) gratings. With respect to stimuli drifting in the antipreferred direction, after nBOR inactivation, most LM units showed less inhibition to slow and/or fast stimuli.

\section{Implications for AOS-pretectal connectivity}

Data from the present study offer several insights to the nature of the connection from the nBOR to LM. First, because LM neurons are directional after nBOR inactivation, it is apparent that other inputs contribute to the direction selectivity of LM neurons. This is not surprising, given that the LM receives a direct retinal input (Gamlin and Cohen 1988a). Using intracellular recording, Kogo et al. (1998) demonstrated that retinal inputs into the turtle AOS are direction selective. This is likely the case for the avian AOS and pretectum as well. The pretectum also receives input from the telencephalon in many species (Hoffmann et al. 1991; Hollander et al. 1979; Schoppmann 1981; Ilg and Hoffmann 1993; Lui et al. 1994; Mustari et al. 1994; Shintani et al. 1999) including pigeons (Miceli et al., 1979), and the lateral cerebellar nucleus in pigeons (Arends and Zeigler 1991). Clearly, the visual response properties of LM neurons arise from the interaction of 

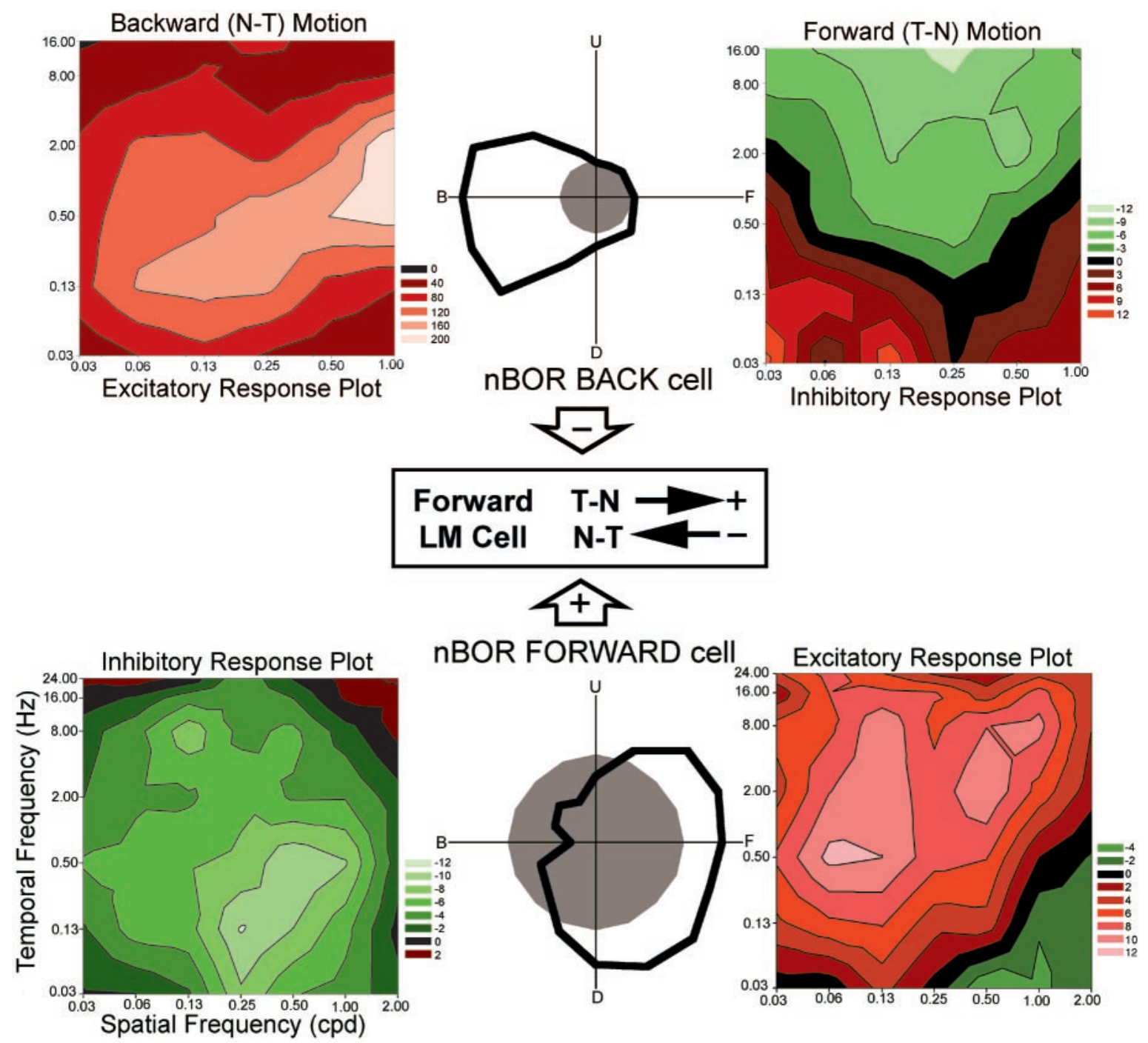

FIG. 7. Descriptive model of projection from nBOR to a neuron in the LM. Data from two neurons in nBOR show possible inputs to LM neuron excited by forward motion and inhibited by backward motion. The proposed connectivity could account for observed changes in spatio-temporal tuning after blockade of nBOR. Directional tuning of the two neurons is shown in addition to spatio-temporal tuning to gratings drifting in preferred direction (Excitatory Response Plots) and anti-preferred direction (Inhibitory Response Plots). U, B, D, and F represent up, back (nasal to temporal), down, and forward (temporal to nasal) motion. See caption to Fig. 4 for additional details and Discussion for a comprehensive description.

many inputs. Second, because most LM neurons showed very little change in their preferred directions after nBOR inactivation, it appears that the LM receives inputs from nBOR neurons with a similar preferred axis. Thus, nBOR neurons preferring horizontal motion (forward and back cells) project to LM neurons preferring horizontal motion, and nBOR neurons preferring vertical motion (up and down cells) project to LM neurons preferring vertical motion. Finally, it appears that information from $\mathrm{nBOR}$ to $\mathrm{LM}$ is specific in the spatio-temporal domain for stimuli drifting in the preferred and antipreferred directions.

The most parsimonious explanation for our results would be that the LM receives excitatory input from fast $\mathrm{nBOR}$ cells of the same direction preference and/or inhibitory input from slow nBOR cells of the opposite direction preference. In Fig. 7 we consider the input to the most common type of LM neurons, those that are excited by forward motion and inhibited by backward motion (i.e., a forward LM neuron). Figure 7, top and bottom, shows directional and spatio-temporal tuning, respectively, for two nBOR neurons (from Crowder and Wylie 2001). The ER plots, direction tuning curve, and IR plots are shown for a nBOR neuron that preferred backward (N-T) motion (top) and a nBOR neuron that preferred forward (T-N) motion (bottom). The back neuron was maximally excited by slow gratings (high SFs, mid TFs) and maximally inhibited by fast gratings (mid SFs, high TFs) drifting forward. The forward neuron was maximally excited by fast gratings (low SFs, mid-high TFs) and maximally inhibited by slow gratings (high SFs, low TFs) drifting backward. To account for our observations of the effects of nBOR inactivation on the responses of LM neurons, we propose that a forward LM cell receives inhibitory input from the slow back cell, and/or excitatory input from the fast forward cell. Although our study does not address which of these two scenarios is more likely, for a few reasons we favor the inhibitory projection. First, back cells are much more common than forward cells in the nBOR (Gioanni 
et al., 1984; Rosenberg and Ariel 1990; Wylie and Frost 1990). Second, slow cells are more common than fast cells in the nBOR (Crowder and Wylie 2001). Finally, previous studies involving electrical stimulation of the AOS have shown that the projection to the pretectum is largely inhibitory. This has been shown both in rats (van der Togt and Schmidt 1994) and pigeons (Baldo and Britto 1990).

It is important to note that the proposed model is descriptive and does not address the reciprocal connection between the nBOR and LM (Brecha et al., 1980; Gamlin and Cohen $1988 b$ ). Thus in addition to preventing retina-to-nBOR information from reaching the LM, nBOR inactivation may also interfere with bidirectional dynamic interactions between the two nuclei.

We thank Drs. Connie Varnhagen and Clayton Dickson for assistance with the statistical analysis and Dr. Brian Christie for critical review of the initial manuscript.

\section{I S C L O S URES}

This research was supported funding from the Natural Sciences and Engineering Research Council (NSERC) of Canada to D.R.W. Wylie. N. A. Crowder was supported by an NSERC postgraduate scholarship.

\section{REFERENCES}

Arends JJ and Zeigler HP. Organization of the cerebellum in the pigeon (Columba livia). II. Projections of the cerebellar nuclei. J Comp Neurol 306: 245-272, 1991.

Azevedo TA, Cukiert A, and Britto LR. A pretectal projection upon the accessory optic nucleus in the pigeon: an anatomical and electrophysiological study. Neurosci Lett 43: 13-18, 1983.

Baldi E, Ambrogi Lorenzini C, Sacchetti B, Tassoni G, and Bucherelli C. Entorhinal cortex and fimbria-fornix role in rat's passive avoidance response memorization. Brain Res 799: 270-277, 1998.

Baldo MV and Britto LR. Accessory optic-pretectal interactions in the pigeon. Brazil J Med Biol Res 23: 1037-1040, 1990.

Baleydier C, Magnin M, and Cooper HM. Macaque accessory optic system. II. Connections with the pretectum. J Comp Neurol 302: 405-416, 1990.

Bielavska E and Roldan G. Ipsilateral connections between the gustatory cortex, amygdala and parabrachial nucleus are necessary for acquisition and retrieval of conditioned taste aversion in rats. Behav Brain Res 81: 25-31, 1996.

Blanks RH, Clarke RJ, Lui F, Giolli RA, Van Pham S, and Torigoe Y. Projections of the lateral terminal accessory optic nucleus of the common marmoset (Callithrix jacchus). J Comp Neurol 354: 511-532, 1995.

Blanks RH, Giolli RA, and Pham SV. Projections of the medial terminal nucleus of the accessory optic system upon pretectal nuclei in the pigmented rat. Exp Brain Res 48: 228-237, 1982.

Brecha N, Karten HJ, and Hunt SP. Projections of the nucleus of basal optic root in the pigeon: an autoradiographic and horseradish peroxidase study. J Comp Neurol 189: 615-670, 1980 .

Burns S and Wallman J. Relation of single unit properties to the occulomotor function of the nucleus of the basal optic root (AOS) in chickens. Exp Brain Res 42: 171-180, 1981.

Carpenter RHS. Movement of the Eyes. London: PION Ltd., 1977.

Collewijn H. Direction-selective units in the rabbit's nucleus of the optic tract. Brain Res 100: 489-508, 1975a.

Collewijn H. Oculomotor areas in the rabbit's midbrain and pretectum. $\mathrm{J} \mathrm{Neu-}$ robiol 6: 3-22, 1975b.

Cooper HM and Magnin M. A common mammalian plan of accessory optic system organization revealed in all primates. Nature 324: 457-459, 1986

Crowder NA, Dawson MR, and Wylie DR. Temporal frequency and velocity-like tuning in the pigeon accessory optic system. J Neurophysiol In press.

Crowder NA and Wylie DR. Fast and slow neurons in the nucleus of the basal optic root in pigeons. Neurosci Lett 304: 133-136, 2001.

Crowder NA and Wylie DR. Spatio-temporal tuning in the pigeon accessory optic system: tuning for temporal frequency and velocity. J Neurophysiol 90: $000-000,2003$
Distler C and Hoffmann KP. Visual receptive field properties in kitten pretectal nucleus of the optic tract and dorsal terminal nucleus of the accessory optic tract. J Neurophysiol 70: 814-827, 1993.

Fan TX, Weber AE, Pickard GE, Faber KM, and Ariel M. Visual responses and connectivity in the turtle pretectum. J Neurophysiol 73: 25072521, 1995.

Fite KV. Pretectal and accessory-optic visual nuclei of fish, amphibia and reptiles: themes and variations. Brain Behav Evol 26: 71-90, 1985.

Fite KV, Kwei-Levy C, and Bengston L. Neurophysiological investigation of the pretectal nucleus lentiformis mesencephali in Rana pipiens. Brain Behav Evol 34: 164-170, 1989.

Frost BJ. Neural mechanisms for detecting object motion and figure-ground boundaries contrasted with self-motion detecting systems. In: Brain Mechanisms of Spatial Vision, edited by Ingle D, Jeannerod M, and Lee D. Dordrecht, The Netherlands: Martinus Nijhoft, 1985, p. 415-449.

Gallo $\mathbf{M}$ and Candido A. Reversible inactivation of dorsal hippocampus by tetrodotoxin impairs blocking of taste aversion selectively during the acquisition but not the retrieval in rats. Neurosci Lett 186: 1-4, 1995.

Gamlin PDR and Cohen DH. Retinal projections to the pretectum in the pigeon (Columba livia). J Comp Neurol 269: 1-17, 1988a.

Gamlin PDR and Cohen DH. Projections of the retinorecipient pretectal nuclei in the pigeon (Columba livia). J Comp Neurol 269: 18-46, 1988b.

Gibson JJ. The visual perception of object motion and subjective movement. Psychol Rev 61: 304-314, 1954.

Gioanni H, Rey J, Villalobos J, and Dalbera A. Single unit activity in the nucleus of the basal optic root (nBOR) during optokinetic, vestibular and visuo-vestibular stimulations in the alert pigeon (Columba livia). Exp Brain Res 57: 49-60, 1984.

Giolli RA, Blanks RH, and Torigoe Y. Pretectal and brain stem projections of the medial terminal nucleus of the accessory optic system of the rabbit and rat as studied by anterograde and retrograde neuronal tracing methods. J Comp Neurol 227: 228-251, 1984.

Giolli RA, Blanks RH, Torigoe Y, and Williams DD. Projections of medial terminal accessory optic nucleus, ventral tegmental nuclei, and substantia nigra of rabbit and rat as studied by retrograde axonal transport of horseradish peroxidase. J Comp Neurol 232: 99-116, 1985a.

Giolli RA, Peterson GM, Ribak CE, McDonald HM, Blanks RH, and Fallon JH. GABAergic neurons comprise a major cell type in rodent visual relay nuclei: an immunocytochemical study of pretectal and accessory optic nuclei. Exp Brain Res 61: 194-203, 1985b.

Giolli RA, Torigoe Y, Clarke RJ, Blanks RH, and Fallon JH. GABAergic and non-GABAergic projections of accessory optic nuclei, including the visual tegmental relay zone, to the nucleus of the optic tract and dorsal terminal accessory optic nucleus in rat. J Comp Neurol 319: 349-358, 1992.

Grasse KL and Cynader MS. Electrophysiology of medial terminal nucleus of accessory optic system in the cat. J Neurophysiol 48: 490-504, 1982.

Grasse KL and Cyander MS. The accessory optic system in frontal-eyed animals. In: Vision and Visual Dysfunction. The Neuronal Basis of Visual Function, edited by Leventhal A. New York: Macmillan, 1990, p. 111-139.

Grasse KL, Cyander MS, and Douglas RM. Alterations in response properties in the lateral and dorsal terminal nuclei of the cat accessory optic system following visual cortex lesions. Exp Brain Res 55: 69-80, 1984.

Gu Y, Wang Y, and Wang SR. Directional modulation of visual responses of pretectal neurons by accessory optic neurons in pigeons. Neuroscience 104: 153-159, 2001.

Hamassaki DE, Gasparotto OC, Nogueira MI, and Britto LRG. Telencephalic and pretectal modulation of the directional selectivity of accessory optic neurons in the pigeon. Brazil J Med Biol Res 21: 649-652, 1988.

Hoffmann KP and Distler C. Quantitative analysis of visual receptive fields of neurons in nucleus of the optic tract and dorsal terminal nucleus of the accessory optic tract in macaque monkey. J Neurophysiol 62: 416-428, 1989.

Hoffmann KP, Distler C, and Erickson RG. Functional projections from striate cortex and superior temporal sulcus to the nucleus of the optic tract (NOT) and dorsal terminal nucleus of the accessory optic tract (DTN) of macaque monkeys. J Comp Neurol 313: 707-724, 1991.

Hoffmann KP, Distler C, Erickson RG, and Mader W. Physiological and anatomical identification of the nucleus of the optic tract and dorsal terminal nucleus of the accessory optic tract in monkeys. Exp Brain Res 69: 635-644, 1988.

Hoffmann KP and Schoppmann A. Retinal input to direction selective cells in the nucleus tractus opticus of the cat. Brain Res 99: 359-366, 1975. 
Hoffmann KP and Schoppmann A. A quantitative analysis of the directionspecific response of neurons in the cat's nucleus of the optic tract. Exp Brain Res 42: 146-157, 1981.

Hollander H, Tietze J, and Distel H. An autoradiographic study of the subcortical projections of the rabbit striate cortex in the adult and during postnatal development. J Comp Neurol 184: 783-794, 1979.

Ibbotson MR, Mark RF, and Maddess TL. Spatiotemporal response properties of direction-selective neurons in the nucleus of the optic tract and the dorsal terminal nucleus of the wallaby, Macropus eugenii. J Neurophysiol 72: 2927-2943, 1994.

Ibbotson MR and Price NS. Spatiotemporal tuning of directional neurons in mammalian and avian pretectum: a comparison of physiological properties. J Neurophysiol 86: 2621-2624, 2001.

Ilg UJ and Hoffmann KP. Functional grouping of the cortico-pretectal projection. J Neurophysiol 70: 867-869, 1993.

Ilg UJ and Hoffmann KP. Responses of neurons of the nucleus of the optic tract and the dorsal terminal nucleus of the accessory optic tract in the awake monkey. Eur J Neurosci 8: 92-105, 1996.

Karten HJ and Hodos W. A Stereotaxic Atlas of the Brain of the Pigeon (Columba livia). Baltimore, MD: Johns Hopkins Press, 1967.

Kato I, Watanabe S, Sato S, and Norita M. Pretectofugal fibers from the nucleus of the optic tract in monkeys. Brain Res 705: 109-117, 1995.

Katte $O$ and Hoffman KP. Direction specific neurons in the pretectum of the frog (Rana esculenta). J Comp Physiol 140: 53-57, 1980.

Kogo N, McGartland Rubio D, and Ariel M. Direction tuning of individual retinal inputs to the turtle accessory optic system. J Neurosci 18: 2673 2684.

Lui F, Giolli RA, Blanks RH, and Tom EM. Pattern of striate cortical projections to the pretectal complex in the guinea pig. J Comp Neurol 344: 598-609, 1994.

McKenna OC and Wallman J. Accessory optic system and pretectum of birds: comparisons with those of other vertebrates. Brain Behav Evol 26: 91-116, 1985a.

McKenna OC and Wallman J. Functional postnatal changes in avian brain regions responsive to retinal slip: a 2-deoxy-D-glucose study. J Neurosci 5: 330-342, 1985 b.

Miceli D, Gioanni H, Reperant J, and Peyrichoux J. The avian visual wulst. I. An anatomical study of afferent and efferent pathways. II. An electrophysiological study of the functional properties of single neurons. In: Neural Mechanisms of Behavior of the Pigeon, edited by Granda AM and Maxwell JH. New York: Plenum Press, 1979, p. 223-354.

Morgan B and Frost BJ. Visual response properties of neurons in the nucleus of the basal optic root of pigeons. Exp Brain Res 42: 184-188, 1981.

Mustari MJ and Fuchs AF. Discharge patterns of neurons in the pretectal nucleus of the optic tract (NOT) in the behaving primate. J Neurophysiol 64: 77-90, 1990.

Mustari MJ, Fuchs AF, Kaneko CR, and Robinson FR. Anatomical connections of the primate pretectal nucleus of the optic tract. J Comp Neurol 349: 111-128, 1994.

Nakayama K. Differential motion hyperacuity under conditions of common image motion. Vision Res 21: 1475-1482, 1981

Natal CL and Britto LRG. The pretectal nucleus of the optic tract modulates the direction selectivity of the accessory optic neurons in rats. Brain Res 419: 320-323, 1987.

Nogueira MI and Britto LRG. Extraretinal modulation of accessory optic units in the pigeon. Brazil J Med Biol Res 24: 623-631, 1991.

Perrone JA and Thiele A. Speed skills: measuring the visual speed analyzing properties of primate MT neurons. Nat Neurosci 4: 526-531, 2001.

Rashidy-Pour A, Motamedi F, and Motahed-Larijani Z. Effects of reversible inactivations of the medial septal area on reference and working memory versions of the Morris water maze. Brain Res 709: 131-140, 1996b.
Rashidy-Pour A, Motamedi F, Semnanian S, Zarrindast MR, Fatollahi Y, and Behzadi G. Effects of reversible inactivation of the medial septal area on long-term potentiation and recurrent inhibition of hippocampal population spikes in rats. Brain Res 734: 43-48, 1996a.

Roldan G and Bures J. Tetrodotoxin blockade of amygdala overlapping with poisoning impairs acquisition of conditioned taste aversion in rats. Behav Brain Res 65: 213-219, 1994.

Rosenberg AF and Ariel M. Visual-response properties of neurons in turtle basal optic nucleus in vitro. J Neurophysiol 63: 1033-1045, 1990.

Schmidt M, Lewald J, van der Togt C, and Hoffmann KP. The contribution of GABA-mediated inhibition to response properties of neurons in the nucleus of the optic tract in the rat. Eur J Neurosci 6: 1656-1661, 1994.

Schmidt M, van der Togt C, Wahle P, and Hoffmann KP. Characterization of a directional selective inhibitory input from the medial terminal nucleus to the pretectal nuclear complex in the rat. Eur J Neurosci 10: 1533-1543, 1998

Schoppmann A. Projections from areas 17 and 18 of the visual cortex to the nucleus of the optic tract. Brain Res 223: 1-17, 1981.

Shintani T, Hoshino K, Meguro R, Kaiya T, and Norita M. A light and electron microscopic analysis of the convergent retinal and visual cortical projections to the nucleus of the optic tract (NOT) in the pigmented rat. Neurobiology 7: 445-460, 1999.

Simpson JI. The accessory optic system. Rev Neurosci 7: 13-41, 1984.

Simpson JI, Leonard CS, and Soodak RE. The accessory optic system. II. Spatial organization of direction selectivity. J Neurophysiol 60: 2055-2072, 1988.

Soodak RE and Simpson JI. The accessory optic system of rabbit. I. Basic visual response properties. J Neurophysiol 60: 2037-2054, 1988.

van der Togt $\mathbf{C}$ and Schmidt $\mathbf{M}$. Inhibition of neuronal activity in the nucleus of the optic tract due to electrical stimulation of the medial terminal nucleus in the rat. Eur J Neurosci 6: 558-564, 1994.

Volchan E, Rocha-Miranda CE, Picanco-Diniz CW, Zinsmeisser B, Bernardes RF, and Franca JG. Visual response properties of pretectal units in the nucleus of the optic tract of the opossum. Exp Brain Res 78: 380-386, 1989.

Weber JT. Pretectal complex and accessory optic system in alert monkeys. Brain Behav Evol 26: 117-140, 1985.

Westheimer G and McKee SP. Failure of Donders' law during smooth pursuit eye movements. Vision Res 13: 2145-2253, 1973.

Winterson BJ and Brauth SE. Direction-selective single units in the nucleus lentiformis mesencephali of the pigeon (Columba livia). Exp Brain Res 60: 215-226, 1985.

Wylie DR and Crowder NA. Spatiotemporal properties of fast and slow neurons in the pretectal nucleus lentiformis mesencephali in pigeons. $\mathrm{J} \mathrm{Neu}$ rophysiol 84: 2529-2540, 2000.

Wylie DR and Frost BJ. Visual response properties of neurons in the nucleus of the basal optic root of the pigeon: a quantitative analysis. Exp Brain Res 82: 327-336, 1990.

Wylie DR, Linkenhoker B, and Lau KL. Projections of the nucleus of the basal optic root in pigeons (Columba livia) revealed with biotinylated dextran amine. J Comp Neurol 384: 517-536, 1997.

Wylie DRW and Frost BJ. The pigeon optokinetic system: visual input in extraocular muscle coordinates. Vis Neurosci 13: 945-953, 1996.

Yakushin SB, Gizzi M, Reisine H, Raphan T, Buttner-Ennever J, and Cohen B. Functions of the nucleus of the optic tract (NOT). II. Control of ocular pursuit. Exp Brain Res 131: 433-447, 2000.

Zhuravin MA and Bures J. Extent of the tetrodotoxin induced blockade examined by papillary paralysis elicited by intracerebral injection of the drug. Exp Brain Res 83: 687-690, 1991. 